\title{
Aile İçi Şiddet: Faillerin Şiddet Davranışını Durdurmada Müdahale Yaklaşımlarının Etkisi
}

\author{
Zeynep Turhan ${ }^{1}$ \\ Bartın Üniversitesi
}

\begin{abstract}
Özet
Erkeğin kadına karşı uyguladığı şiddetle mücadelede aile içi şiddet müdahaleleri önemli bir rol oynamaktadır. Aile içi şiddete yönelik müdahale hizmetlerinde farklı teknikler ve yaklaşımlar kullanılmaktadır. Bu yaklaşımların şiddeti sonlandırmada ne kadar etkili olduğu konusunda gelişmiş ülkelerdeki çalışmaları incelemek, Türkiye'de aile içi şiddetle mücadeleyi güçlü bir yapıya ulaştırmada yardımcı olabilir. Bu çalışma kapsamlı ve sistematik olarak farklı yaklaşımların faillerin karakteristik özelliklerine ve ihtiyaçlarına göre bir arada verilmesinin önemini vurgulamaktadır. Mevcut makalenin ana amacı şiddet faillerinin şiddet davranışlarını durdurmak için, bütüncül ve çoklu yaklaşımların bir arada uygulanmasına dikkat çekmektir. Özellikle aile içi şiddet faillerinin tedavisinde başvurulan bilişsel davranışçı yaklaşımların, motivasyona dayalı tekniklerin ve kültüre duyarlı yaklaşımların bir arada kullanılmasının müdahalenin etkinliğini artırabileceği önerilmektedir. Bu makale aile içi şiddet müdahalesinde şiddet failleri ile çalışan uzmanlara başvuracakları teknikler ve kuramlar konusunda 1şık tutmayı ve bilim insanlarının bu konuda daha kapsamlı araştırmalara yönelmesine yardımcı olmayı umut etmektedir.
\end{abstract}

Anahtar kelimeler: Aile içi şiddet, bilişsel-davranışçı yaklaşımlar, failler, motivasyon, müdahale

\begin{abstract}
Domestic violence perpetrator interventions play a significant role in ending male violence against women. Different techniques and approaches have been implemented in domestic violence interventions. The examination of the effectiveness of these approaches in developed countries can help Turkish attempts to institute robust programmes. This research focuses on the importance of implementing integrated approaches based on perpetrators' characteristics and needs. The major purpose of this article is to illustrate the importance of using integrated and pluralistic approaches to end perpetrators' violent behaviour. It is suggested that an integrated cognitive-behavioural approach, motivational interviewing and culturally-sensitive approaches can increase the effectiveness of domestic violence perpetrator interventions. It is hoped that this article can improve professionals' knowledge about perpetrator interventions and encourage other researchers to examine this topic in greater depth.
\end{abstract}

Keywords: Domestic violence, cognitive-behavioural approaches, perpetrators, motivation, intervention

Yazışma Adresi: ${ }^{1}$ Dr. Öğr. Üyesi Zeynep Turhan, Bartın Üniversitesi, Sağlık Bilimleri Fakültesi, Sosyal Hizmet Bölümü, Bartın, zturhan@bartin.edu.tr, ORC-ID: 0000-0002-5343-9442

Gönderim Tarihi: 14.05 .2019

Kabul Tarihi: 21.02 .2020 
Bilim insanları aile içi şiddet problemine son vermek, şiddet davranışını durdurmak ve azaltmak için ne tür müdahale hizmetlerinin verilmesi gerektiği konusunda çalışmaktadır. Aile içi şiddet tüm dünyada olduğu gibi Türkiye'de de önemli sorun alanlarından birisi olarak karşımıza çıkmaktadır. Ailenin Korunması ve Kadına Karşı Şiddetin Önlenmesine dair 6284 sayılı kanun kapsamında ailenin güvenliğinin sağlanması için önleme ve koruma tedbir kararlarına yer verilmiştir. İlgili kanun kadın ve çocuk mağdurların güvenliğini sağlamada kilit bir rol üstlenmiştir. 6284 sayılı kanunda şiddet fiziksel, cinsel, psikolojik, sözlü veya ekonomik gibi farklı şiddet türlerine vurgu yapılmıştır. İstanbul Sözleşmesine (2011) göre kadına karşı şiddet ise şu şekilde tanımlanmıştır:

... kadınlara karşı bir insan hakları ihlali ve ayrımcılık anlaşılacak ve bu terim, ister kamu ister özel yaşamda meydana gelsinler, söz konusu eylemlerde bulunma tehdidi, zorlama veya özgürlüğün rastgele bir biçimde kısıtlanması da dahil olmak üzere, kadınlara fiziksel, cinsel, psikolojik veya ekonomik zarar ve acı verilmesi sonucunu doğuracak toplumsal cinsiyete dayalı tüm şiddet eylemleri olarak anlaşılacaktır. (3a)

İstanbul Sözleşmesinde tanımlanan kadına karŞ1 şiddet terimi kadına karşı hiçbir ayrımcılığın kabul edilemez olduğuna ve kadın hakları ve özgürlüğünün önemine dikkat çekmiştir. Fiziksel, cinsel, psikolojik ve ekonomik şiddet gibi farklı şiddet türlerinin zarar verici sonuçlarına vurgu yapılmıştır. İstanbul Sözleşmesinde (2011) aile içi şiddet ise şu şekilde tanımlanmıştır:

eylemi gerçekleştiren, mağdurla aynı ikametgahı paylaşmakta olsun veya olmasın veya daha önce paylaşmış olsun veya olmasın, aile içinde veya aile biriminde veya mevcut veya daha önceki eşler veya birlikte yaşayan bireyler arasında meydana gelen fiziksel, cinsel, psikolojik veya ekonomik şiddet eylemleri olarak anlaşılacaktır. (İstanbul Sözleşmesi, 2011: 3b)

Görüldüğü gibi aile içi şiddet kavramının temelinde aynı evi paylaşsınlar ya da paylaşmasınlar önemli olanın aile üyelerinden biri tarafindan fiziksel, cinsel, psikolojik ve ekonomik şiddete başvurmak yer almaktadır.

Aile içi şiddetin yaygınlık oranı Dünya Sağlık Örgütü ve diğer araştırmalar tarafından gözler önüne serilmiştir. Örneğin, 2013 yılındaki Dünya Sağlık Örgütü raporlarına göre, kadınların \%35'i hayatlarında en az bir kez eşleri ya da erkek arkadaşları ya da başka birileri tarafından fiziksel ya da cinsel şiddete uğramaktadır (WHO, 2013). Türkiye'de kadına yönelik aile içi şiddet istatistiklerine göre, \%37.5 kadın yaşamları boyunca en az bir kez cinsel ya da fiziksel şiddete maruz bırakılmıştır (TÜIKK, 2014). Bununla birlikte, başka bir çalışmada kadınların yüzde 12'sinin cinsel şiddete maruz kaldığ 1 saptanmıştır (Yüksel-Kaptanoğlu ve Çavlin, 2015). Eryurt ve Seçkiner'in (2015) yaptığı çalışmaya göre her on kadından altısının aile içi şiddetten dolayı birkaç kez ya da daha fazla yaralanmaları olduğu tespit edilmiştir. Yaklaşık olarak iki kadından bir tanesi aile içi şiddetten dolayı en az bir kez ağır yaralanmalar yaşamıştır (Eryurt ve Seçkiner, 2015). Ayrıca hamile kadınlardan \%8'nin eşleri tarafından fiziksel şiddete maruz bırakıldıkları tespit edilmiştir (Eryurt ve Seçkiner, 2015). Aile içi şiddet istatistikleri problemin yaygınlığına işaret ederken, müdahale hizmetleri şiddetin olumsuz etkilerini en aza indirgemek ve şiddeti sonlandırmak için etkili yaklaşımlara ve tekniklere başvurmalıdır.

Aile içi şiddet faillerinin şiddet davranışlarını durdurma yönündeki iyileştirme hizmetleri mağdurların hayatta kalmasını sağlama açısından da önemlidir. İçişleri Bakanlığı verilerine göre, 2000-2005 yılları arasında ortalama 1300 aile içi şiddet mağduru kadın ve çocuk erkekler tarafından öldürülmüştür (Mavili, 2014). Ayrıca İçişleri Bakanlığı, 32.237 kadın ve çocuğun aile içi şiddet failleri tarafından ağır veya hafif derece yaralandıklarını rapor etmiştir (Mavili, 2014). Aile içi şiddetin kadın ve çocuk mağdurlar üzerindeki olumsuz ve zarar verici sonuçları diğer kültürlerin aile içi şiddet vakalarında da bulunmuştur (Campbell 2004; Cavanaugh vd., 2011; Heckert ve Gondolf 2004). Bu veriler dikkate alındığında aile içi şiddet failleri için uygulanacak olan sistematik ve güçlü müdahale hizmetlerinin tüm aile bireylerinin sağlığı ve güvenliği için hayati önem taşıdığı ortadadır. Bu makale aile içi şiddet faillerine karşı müdahale hizmetlerinde uygulanabilecek yaklaşımların ve tekniklerin etkisini inceleyerek, uzmanların en uygun yöntem ve yaklaşımları uygulamaları konusunda yardımcı olmayı amaçlamaktadır.

Alanyazın incelendiğinde feminist teorilerin ve bilişsel-davranışçı yaklaşımların ağırlıklı olarak şiddet davranışını önlemede başvurulan ana yaklaşımlar olduğu hemen göze çarpmaktadır (Eckhardt, Murphy, Black, ve Suhr, 2006; Lawson, Kellam, Quinn, ve Malnar, 2012; Palmstierna, Haugan, Jarwson, Rasmussen, ve Nøttestad, 2012). Benzer şekilde, Duluth model (Pence ve Paymar, 1993) ve bilişsel-davranışçı yaklaşımlar (Murphy ve Eckhardt, 2005) aile içi şiddet davranışı sergileyen kişiler için uygulanan önemli iyileştirme yöntemleridir.

Duluth modelin temelini oluşturan feminist sosyal-psikolojik yaklaşımlar; cinsiyetçi güç dengesinin azaltılması, ataerkil sosyal yapının ve erkek ayrımcılığının kaldırılması gerektiğinin altını çizerken, daha eşitlikçi bir anlayışın gelişmesinin önemini vurgulamaktadır (Pence ve Paymar, 1993). Bilişsel-davranışçı yaklaşımlar ise pek çok tedavi tekniklerini içinde barındırır. Ana tekniklerin başında stres yönetimi, öfke kontrolü, ara verme stratejisi, ilişki becerisi geliştirme eğitimi ve aile içi şiddete sebep 
olan düşünce yapısını değiştirmek yer almaktadır (Murphy ve Eckhardt, 2005). Görüldüğü gibi bu yaklaşımlar arasında bazı farklıklar vardır. Örneğin, feminist yaklaşımlar daha çok ataerkil düşünce yapılarına ve cinsiyetçi tutumlara odaklanırken, bilişsel-davranışçı yaklaşımlar ataerkil yapıyla birlikte farklı sebepleri de içine alarak şiddetin nedenlerini değerlendirmektedir. Bilişsel-davranışçı yaklaşımlara göre, şiddete sebep olan faktörler arasında duruma bağlı şiddet, genetik yap1, ataerkil sosyal yap1, madde kullanımı ve psikopatolojik etkenler vardır (Allen, 2010; Woodin ve Leary, 2009).

Aile içi şiddeti önlemede sıklıkla başvurulan teknikler ve kuramsal içeriklerin yanı sıra son yıllarda etkililiği konusunda pek çok araştırma yapılan motivasyonel görüşme (motivational interviewing) yaklaşımının incelenmesi da faydalı olacaktır. Örneğin, motivasyon ve isteklilik kavramlarına ağırlık veren motivasyona dayalı teknikler son yıllarda ön plana çıkmıştır. Motivasyonel görüşme müdahale hizmetlerine katılan kişilerin değişim için hazır olmalarının önemine dikkat çekerek, bu hazır olma seviyelerinin nasıl yakalanabileceği konusuna eğilmişlerdir (Musser, Semiatin, Taft, ve Murphy, 2008). Şiddet davranışı sergileyen kişilerin çoğunun davranış değişimi ya da müdahale hizmetine katılım sağlama konusunda hazır olmadıkları alanyazında sürekli olarak vurgulanan bir bulgudur (Daniels ve Murphy, 1997; Prochaska ve DiClemente, 1982).

Güçlü yönlerini ortaya çıkarma yaklaşımı (strength based approach) ise son yıllarda ön plana çıkan önemli yaklaşımlar arasında sayılabilir (Simmons ve Lehmann, 2009). Güçlü yönleri ortaya çıkarma teknikleri kişileri bir bütün olarak değerlendirerek, onların güçlü yönlerinin olduğunu kabul eder ve güvenli bir ortam sağlanarak yetkin oldukları taraflar fark ettirilir ve kendilerini geliştirmelerine yardımcı olur (Simmons ve Lehmann, 2009). Kendilik yönünde farkındalık arttırılması hem eğitici hem de kişiler arası ilişkileri güçlendirici bir rol oynar. Değişime ve iyileştirmeye hazır olan bireylerin motivasyonu yüksek olacağından müdahale hizmetlerinden de daha iyi bir şekilde faydalanabileceği düşünülmektedir. Sonuç olarak aile içi şiddet davranışı gösteren bireylere sağlanacak müdahale hizmetlerinin kalitesini artırmak amacıyla farklı tekniklerin ve kuramların bir arada kullanılması önemlidir.

\section{Aile İçi Şiddete Yönelik Müdahale Yaklaşımlarının Etkililiği}

Aile içi şiddet fail müdahale süreçlerine katılan danışanlar ile uzman arasındaki ilişkinin güçlü olması katılımcıların davranış değişimlerine olumlu katkı sağlar. Örneğin, işbirliği içinde çalışma (working alliance) bu ilişkiyi güçlendirici ve müdahalede başarılı sonuçlara erişmede önemli bir yöntemdir (Taft ve Murphy, 2007).
Sosyal hizmet uzmanlarının müdahale hizmetlerine kat1lanlarla kuracakları olumlu ilişki ve işbirliği içinde çalışmayı geliştirme aile içi şiddet iyileştirme merkezlerinin etkili çıktılara ulaşmasında önemli bir faktördür (Lomo, Haavind, ve Tjersland, 2016).

Geliştirilecek terapötik iletişim ve işbirliği müdahale hizmetlerinin olumlu olarak ilerlemesine ve istenilen sonuca varmasına katkı sağlar. Örneğin, ön görüşmede kişilerin yaşadığı düşük kaçınma ve yüksek kaygı ile kişiler arası problemler, müdahalenin başlangıç aşamasında uzman ile danışan arasındaki kaygının düzeyi ve kişiler arası ilişki şekilleri tedavinin sonucunu şekillendirir. (Lawson ve Brossart, 2009). Görüldüğü gibi müdahale öncesindeki bağlanma şekilleri ve kişiler arası ilişki şekilleri tedavinin sonucunu belirleyebilmektedir. Benzer şekilde bilişsel-davranışçı tekniklerle birlikte geliştirilen işbirliği içinde çalışma olumlu sonuçlara erişmede katkı sağlamaktadır (Walling, Suvak, Howard, Taft, ve Murphy, 2012). Böyle bir işbirliğinin geliştirilmesi için öncelikli olarak uzmanların şiddet uygulayan kişiyi değişebilen ve güçlü olumlu yönleri olan birisi olarak kabul etmesi gerekmektedir. Sonuç olarak aile içi şiddet failleri ile çalışan meslek elemanlarının müdahalenin başında kuracakları terapötik ilişki ve işbirliği, faillerin müdahaleye aktif katılımlarını ve sağlıklı davranışlar geliştirmede gösterecekleri çabayı etkilemektedir.

\section{Bilişsel-davranış̧̧ı yaklaşımlar}

Bilişsel-davranışçı yaklaşımın içeriğinde aile içi şiddet faillerine öğretilen öfke kontrol teknikleri yer almaktadır. Bunlar arasında rahatlama ve nefes teknikleri, mola ya da ara verme stratejisi (time-out strategy) ve eşine karşı olumsuz yorum, suçlama ve dayandırmaları değiştirerek, daha olumlu ve sağlıklı davranış biçimleri geliştirmek yer almaktadır (Babcock vd., 2004). Öfke kontrolü teknikleri ve ara verme stratejisi bilişsel davranışçı yaklaşımın içeriğinde kullanılan önemli müdahale yöntemleri olarak karşımıza çıkmaktadır. Bu tekniklerin etkisini anlamaya yönelik yapılan çalışmaları irdelemek meslek elemanlarını bu tekniklerin ne zaman ve nasıl fayda sağlayabileceği konusunda aydınlatacaktır.

Bilişsel-davranışçı yaklaşımların değişime açık bireyler üzerinde daha etkili olduğu gözlemlenirken, değişim ve yeni beceriler öğrenme konusunda direnç gösteren aile içi şiddet failleri üzerinde etkisinin az olduğu vurgulanmaktadır. Bunun ana sebeplerinden birisi kat1lımcıların öğretici bir ortam içerisine girmeleri onların tedaviye karşı direnç göstermelerine neden olmaktadır. Bazı sınırlılıkları ve eksiklikleri olsa da, bilişsel-davranışçı teknikleri aile içi şiddet faillerinin şiddet davranışlarında durdurmada başvurulan en yaygın müdahale türlerinden birisidir. $\mathrm{Bu}$ müdahalede kullanılan önemli tekniklerden bazıları iletişim becerilerini geliştirme, 
kendine güven duygusunu oluşturma, karar verebilme becerisini geliştirme ve öfke kontrolü tekinleridir (Babcock, Green, ve Robie, 2004).

Bilişsel-davranışçı tekniklerinin aile içi şiddet faillerinin davranış değişimindeki etkisi farklılıklar göstermiştir. Aile içi şiddet faillerinin şiddeti azaltması ve durdurması için başvurulan bilişsel-davranışçı teknikler çok az etkili olmuştur (Dunford, 2000; Smedslund, Dalsbø, Steiro, Winsvold, ve Clench-Aas, 2007). Müdahale süreçlerinde, çocukluğunda eziyet gören ve sancılı çocukluk geçiren kişilerin bilişsel-davranışçı tekniklere cevap vermede başarısız olduğu saptanmıştır (Saunders, 1996). Bilişsel-davranışçı tekniklerin toplumsal destek grupları müdahale programlarında yüksek düzeyde fayda sağlayamadıkları bulunmuştur (Morrel, Elliott, Murphy, ve Taft, 2003).

Bilişsel-davranışçı tekniklerin istenilen sonuçlara ulaşmadığını gösteren verilerin tersine bazı çalışmalar bilişsel-davranışçı yaklaşımların başarılı sonuçlara eriştiğini saptamıştır. Mesela, grupla uygulanan bilişsel-davranışçı tekniklerin bireysel danışma sürecine göre daha başarılı sonuçlara eriştikleri belirtilmiştir (Murphy, Eckhardt, Clifford, Lamotte, ve Meis, 2017). Travmaya bağlı bilişsel-davranışçı tedavi gruplarında fiziksel ve duygusal şiddet düzeylerinde önemli azalmalar bulunmuştur (Taft, Macdonald, Creech, Monson, ve Murphy, 2016). Ev ödevlerine sayg1lı olan katılımcilar üzerinde de bilişsel-davranışçı teknikler olumlu sonuçlar sağlamıştır (Taft, Murphy, King, Musser, ve DeDeyn, 2003). Tutarsız sonuçların olası sebepleri arasında hem danışanın hem de terapistin özellikleri etkili olabilmektedir. Örneğin danışanın travmatik çocukluk yaşantıları ve bağlanma sorunları ya da terapistin bilgisi ve kendini geliştirme düzeyi bilişsel-davranışçı terapinin etkili sonuçlara erişmesine yön veren durumlar olabilir.

\section{Öfke kontrolü tekniklerinin etkisi}

Öfke kontrolü teknikleri içerisinde öfkeyle ve tetikleyici unsurlarıyla ilgi kişilerin farkındalığını artırma, problemlerle başa çıkma becerisi kazandırma ve rahatlama teknikleri yer almaktadır. Howells vd., (2005) hapishane sistemindeki öfke kontrolü programlarının etkili olup olmadığını incelemek için programa katılanların öncesi ve sonrasındaki iki ay ve altı aylık süreçte bir kontrol grubuyla; bekleme listesindeki faillerle karş1laştırmalı bir değerlendirme yapmıştır. Bu öfke kontrol programı daha çok bilişsel davranışçı yaklaşımlara dayal1 olup, iki saatlik sürelerden oluşan on seans içermektedir. Bu programlar eğitimli yöneticilerle sürdürülmekte ve Yeni Zelanda'da geliştirilen Novaco'nun taslağ1 ve materyalleri kullanılmaktadır (Novaco, 1997). Programın içeriğinde becerileri geliştirmeye yönelik egzersizler, tetikleyici unsurları tanımlama, rahatlama teknikleri, bilinç yapılandırması ve kendi hakkını uygun şekilde müdafaa edebilme vardır. Bunların dışında eğer kişi müdahale sürecini tamamladıktan sonra tekrar şiddet uygulayacağını hissederse yeniden programa katılabilme hakkı da sağlanmaktadır.

Howells ve arkadaşlarının (2005) çalışma sonucuna göre programa katılanlarla katılmayan kontrol grubu arasında istatistiki olarak çok fark bulunmuştur. Örneğin, programa daha istekli katılanların öfkesini kontrol etme konusunda daha çok çaba göstererek başarılı sonuçlara eriştiği gözlemlenmiştir. Çok az ya da hiç istekli olmayanların ise neredeyse hiç değişim ya da gelişim göstermedikleri vurgulanmıştır. Bu programların etkililiğini artırmak için katılımcıların isteklilik seviyesini yükseltmek ve diğer sorun alanlarında da çözüm bulunabilecek farklı yaklaşımların uygulanması önerilmiştir (Howells vd., 2005). Örneğin katılımcılarla geliștirilecek terapötik işbirliği ve anlaşma onların sürece daha aktif katılımı$\mathrm{n}$ ırtırabilir. Bununla birlikte kişilik bozuklukları ya da madde bağımlılığ 1 gibi sorun alanlarına da cevap verebilecek ek destek programlarından faydalanılması başarılı sonuçlara erişmede katkı sağlar (Howells vd., 2005).

Öfke kontrolü daha çok aile içi şiddet faillerinin iyileştirme sürecinde başvurulan önemli müdahale yöntemlerinden birisidir (Howells vd., 2005). Öfke kontrolünün etkili olduğunu gösteren bulgular paylaş1lırken, öfke kontrolü tekniklerinin bazı şiddet failleri üzerindeki etkileri konusunda da soru işaretleri vardır (Howells vd., 2005). Öfke ile saldırganlık ve diğer şiddet suçları arasındaki ilişkileri irdeleyen çalışmalara göre, öfke her zaman saldırganlığa ya da şiddete neden olmamaktadır. Örneğin, Howells vd., (2005) saldırganlığın öfke olmaksızın ortaya çıktığı durumlara dikkat çekmiştir. Bu bağlamda şiddeti ortaya çıkaran pek çok farklı durum ve koşulların değerlendirilmesi gerektiği unutulmamalıdır. Kapsamlı bir şekilde şiddetin sebepleri belirlendikten sonra uygun öfke kontrolü tekniklerine başvurulması önerilmektedir.

Öfke kontrolünün etkili olduğunu gösteren bazı söylem analizi çalışmaları vardır (Deffenbacher, Oetting, ve DiGiuseppe, 2002). Meta analiz çalışmaları da öfke kontrolünün en az orta düzeyde fayda sağladığını göstermiştir (Beck ve Fernandez, 1998; Del Vecchio ve O’Leary, 2004; DiGiuseppe, ve Tafrate, 2003). Benzer şekilde, DiGiuseppe, ve Tafrate, (2003) öfke kontrolü yöntemlerini uygulamanın hiçbir şey yapmamaktansa bu yöntemleri kullanmanın iyi bir yaklaşım olacağını söylemiştir. Öfke kontrolünün şiddet ve saldırganlık üzerindeki olumlu sonuçları vurgulanırken, aile içi şiddet faillerinin çoğunlukla cinsiyetçi tutumlar, ataerkil sosyal yapı ve buna benzer sosyal yapı ve anlayışların da şiddete neden olduğu göz önünde bulundurmalıdır. Faillerin karakteristik özellikleri ve onları suça iten muhtemel nedenler dikkate alınarak uygun müdahale yaklaşımlarının yapılandırılması ve düzenlenmesi önemlidir (Andrews ve Bonta, 2003). 
Öfke durumunun dişında kişileri şiddete sürükleyen farklı faktörler olabilir. Örneğin Walker and Bright, (2009) düşük seviyedeki özgüvenin yüksek olan özgüvenden daha çok şiddetle ilgili olduğunu savunurken bazı durumlarda yüksek özgüvenin de şiddetle ilişkili olabileceğini söylemişlerdir. Bilişsel-davranışçı ve psiko-dinamik yaklaşımların birlikte kullanılabileceği önerilmiştir (Walker ve Bright, 2009). Yaklaşımların birlikte kullanılması şiddet faillerinin temel inançlarının yapılandırılmasında ve gerçek dışı varsayımların yeniden düzenlenmesinde yardımcı olacaktır. Walker ve Bright, (2009) önemli bilişsel düşüncelerin, özgüvenin ve aşağılanma ve küçük düşürülmeyle oluşan düşük özgüveni koruma çabalarının şiddetle ilişkili olduğuna dikkat çekerek, şiddetle müdahalenin günlük ilişkileri içine alan hassas ve derin özgüven dinamiklerinin diğer faktörlerle birlikte dikkate alınması gerektiğini vurgulamışlardır. Sonuç olarak şiddet faillerinin yaşadıkları aşağılanmayla oluşan düşük özgüven üzerinde de psikolojik destek hizmetlerinin dikkate alınması gerektiğinin altı çizilmiştir (Walker ve Bright, 2009).

Öfke kontrolü ile ilgili yapılan araştırmalar ve değerlendirmeler incelendiğinde öfke ile şiddet davranışları arasında her zaman bir ilişkinin olmadığı karşımıza çıkmaktadır. Çok karmaşık ve farklı faktörlerin ve karakteristik özelliklerin şiddeti ortaya çıkarmada etkili olduğu göz önünde bulundurulduğu zaman öfke kontrolü tekniklerinin şiddeti sonlandırmada sınırlı kalacağı görülmektedir. Bu alanda çalışan uzmanların da müdahaleye katılanların kişisel özelliklerine uygun yaklaşımlar geliştirerek eklektik bir biçimde tek bir yaklaşıma bağımlı kalmadan en uygun tekniklere başvurmanın fayda1 olacağı önerilmektedir (Livesley, 2001).

\section{Ara verme (time-out) stratejisinin etkisi}

Bilişsel davranışçı yaklaşımlarda en sık kullanılan şiddetten kaçınma tekniklerinin içinde ara verme tekniği yer almaktadır. Ara verme tekniği de aile içi şiddet failleri için önerilen önemli şiddet önleme yollarından birisidir (Wistow, Kelly, ve Westmarland, 2016). Ara verme yöntemi kişilerin kendilerini kızgın ya da öfkeli hissettikleri zamanlarda şiddet uygulama ihtimali olduğunu fark ettikleri anda bulundukları ortamı terk etmeleri gerektiğini öğretir. Böyle bir durumda kişi eşinin yanından ayrılıp başka bir odaya giderek ya da dışarı çıkarak kendini kontrol etmesi ve şiddete başvurmaması sağlanır. Bu tekniğin faydalı olup olmadığı ya da uygulamada ne gibi sıkıntıların olduğunu anlayabilmek için bazı araştırmalar yapılmıştır. Örneğin, ara verme tekniği aile içi şiddet faillerinin davranışlarını nasıl kontrol edebileceği konusunda yol göstererek şiddetin durdurulmasında yardımcı olur (Gondolf, 1987). Ara verme tekniği ya da diğer şiddetten kaçınma tekniklerinin uygulamaya konulabilmesi için kişilerin belli bir seviyede öz yeterlilik ve başarabilme duygularının oluşabilmesi önceliklidir (Gondolf, 1987).

İngiltere'de yapılan bir çalışmada şiddetten uzak durma tekniklerinin fiziksel şiddeti azalttığına dair bazı bulgulara paylaşılırken, duygusal ya da cinsel şiddeti ne düzeyde azalttığı konusunda belirli bir veriye ulaşılamamiştır (Dobash, Dobash, Cavanagh, ve Lewis, 2000). Bunun yanında bazı bulgular ise ara verme tekniğinin faydası konusundaki soru işaretlerinden söz etmektedir. Örneğin, failler ara verme tekniğini doğru bir şekilde uygulamaya çalışsa bile tekniği uygularken kadının korku ve kaygısını artırabileceğine dikkat çekilmiştir (Debbonaire, Debbonaire, ve Walton, 2003). Böyle olumsuz bir sonucun doğmasının sebebi erkeğin ara vermeyi bir tehdit unsuru olarak kullanması olabilir (Debbonaire vd., 2003). Ara verme tekniğinin sağlıklı bir şekilde uygulanabilmesi için kişinin fiziksel şiddeti durdurmaya çal1şırken eşine karşı duygusal ve sözel şiddeti de tamamen kesmiş olması gerekir. Bu nedenle bu teknik öğretilirken kişinin şiddeti tanımlayabilmesi ve her tür şiddetin eşine vereceği zararı kavrayabilmesi çok önemlidir.

Wistow, Kelly ve Westmarland, (2016) İngiltere'de aile içi şiddet failleri müdahale programlarına katılanların ara verme stratejisini nasıl uyguladıklarını anlamaya yönelik 44 erkekle yarı-yapılandırılmış mülakatlar yapmışlardır. Ayrıca eşlerinin ara verme tekniğini ilişkilerinde nasıl uygulamaya koyduklarını anlamak için eşi müdahale programına katılmış 27 kadınla da yarı-yapılandırılmış mülakatlar gerçekleştirilmiştir (Wistow vd., 2016). Ara verme stratejisi uygulanırken üç farklı yola başvurulduğu bulunmuştur. Birincisi erkeklerin fiziksel şiddete bir engel ve önleme amaciyla ara vermeye başvurduğu gözlemlenmiştir. Böylece fiziksel şiddeti azalttığ1 ve kısa süreli güvenliğin sağlandığ1 yönünde bulgular paylaşılmıştır. İkincisi, şiddet mağdurlarının yönlendirmesiyle erkeklerin bu stratejiyi uyguladıkları görülmüş ama erkek buna uymuyorsa kadınların ortamı terk etmesiyle ara verme stratejini uyguladığı rapor edilmiştir. Üçüncüsü ise erkeğin yanlış ya da uygun olmayan şekilde ara verme tekniğini uygulamaya çalışarak kontrol ve güç gösterme davranış biçimlerine devam etmesi şeklinde tanımlamıştır. Sonuç olarak ara verme yönteminin aile içi şiddeti durdurmada bir çözüm yolu olduğuna dair bazı soru işaretlerinin olduğu görülmüştür.

Wistow vd., (2016) bazı katılımcıların ara verme tekniğinden olumlu olarak fayda sağladıklarını rapor etmiştir. Bu yöntemin etkili bir şekilde uygulamaya konulabilmesi için eşlerin bu yöntemi nasıl uygulayacağ1 konusunda yeterli bilgi sahibi olması gerekir. Ayrıca şiddet faillerinin uyguladıkları şiddet davranışlarının sorumluluğunu üstlendikleri zaman benzer bir durumu aile bireylerine yaşatmamak için bu yöntemi uygun bir şekil- 
de kullanması beklenir. Ara verme stratejisi kişinin kendine ve aile bireylerine belli bir alan, mesafe ve zaman vermesini sağlar. Böylece şiddet uygulayıcı daha sakin olacakları bir zamanda eşleriyle daha sağlıklı ve olumlu ilişkiler kurabileceklerini hedefler. Ara verme tekniğinin şiddetsiz davranışlar geliştirme konusunda kesin ve büyük bir değişim sağladığı söylenemese de kişinin kendini belli oranda kontrol ederek ailede güvenliği sağlamasına yardımcı olur.

Bilişsel-davranışçı tedavinin aile içi şiddet failleri üzerindeki başarısı konusundaki tutarsız sonuçların varlığı uzmanların gerekli aktif çaba ve emeği verememesiyle, kurumlar ve uzmanlar arasındaki işbirliği ve uyumun zayıf olmasıyla ilgilidir (Murphy vd., 2017). Katılımc1ların müdahale sürecine karşı isteksiz olması ve aktif bir katılım göstermemeleri olumsuz çıktıların önemli nedenlerdendir (Eckhardt, Holtzworth-Munroe, A. Norlander, Sibley, ve Cahill, 2008). Sonuç olarak, programın başında katılımcıların isteklerini artırıcı motivasyona dayalı çalışmalar bilişsel-davranışçı tekniklerin başarılı sonuçlara erişmesine yardımcı olabilir (Crane ve Eckhardt, 2013).

\section{Motivasyonel görüşme (motivational interviewing)}

Aile içi şiddet failleri iyileştirme hizmetlerine çoğunlukla zorla ya da mahkeme kararıyla katılmaktadırlar. Böyle zorunlu katılım süreçlerindeki bireylerin ise programa aktif katılımlarının zayıf olduğu yadsınamaz bir gerçek olarak önümüze çıkmaktadır. Bu tür olumsuz örnekleri azaltmak ve kişilerin aktif katılımlarını artırmak için motivasyona dayalı teknikler faydalı olacaktır. Motivasyonel görüşme katılımcıların programlara istekli ve hevesli bir şekilde katılmalarını hedefler. Buna ulaşmak içinde iyileştirme sürecinin başında güvenli ve terapötik bir ortam oluşturmak, katılımcıların programa olan direncini azaltmak, işbirliğini tesis etmek ve davranış değişikliği için belirsizliğe çözüm bulmak motivasyonel görüşmenin önemli kuralları arasındadır (Murphy ve Eckhardt, 2005). Katılımciların programa uyumunu ve adaptasyonunu kolaylaştırmak için motivasyonel görüşme kullanılır (Murphy ve Eckhardt, 2005). Aile içi şiddet faillerinin ceza hukukuyla yargılandıklarını fark etmeleri müdahaleye katılımlarında tetikleyici rol oynar (Saunders, 2009; Silvergleid ve Mankowski, 2006). Bu tür tetikleyici durumların varlığı onları daha motive ederek müdahaleye aktif katılımları sağlayabilir.

Musser vd. (2008) müdahale programı öncesinde iki seans motivasyonel görüşmenin uygulandı̆̆ ${ }_{1}$ programlar ile standart yaklaşımların uygulandığı tedavileri karşılaştırmıştır. Bu çalışma sonucuna göre motivasyonel görüşmenin uygulandığ 1 oturumlardaki danışanların bilişsel-davranışçı teknikleri uygulama süreçlerine daha aktif katıldığ 1 saptanmıştır. Örneğin, bilişsel-davranışç1 terapideki ödevlere daha uyumlu oldukları, yardım al- maya daha istekli oldukları ve terapistin daha olumlu bir terapötik ilişki geliştirdiği bulunmuştur (Musser vd., 2008). Bu farklılıklara rağmen davranış değişiminde, müdahaleye katılım sayısında ve bireysel raporlardaki terapötik ilişki geliştirmelerde önemli bir farklılık gözlenmemiştir (Musser vd., 2008).

Aile içi şiddet suçundan mahkûm olmuş 160 erkekten 70 saatlik müdahale programına katılanlardan motivasyonel görüşmenin uygulandığ 1 ve uygulanmad1ğ1 iki grubun tecrübeleri değerlendirmiştir (Lila, Gracia, ve Catala-Minana, 2018). Bireyselleştirilmiş motivasyonel görüşme içerisinde değişim için hazır olma basamakları (stages of change) ve güçlü yönlerini ortaya çıkarma teori prensipleri (strength-based theory principles) yer almaktadır (Lila, Gracia, ve Catala-Minana, 2018). Dokuz aylık ve altı aylık takip süresi sonuçlarına göre motivasyonel görüşmenin eklendiği standart müdahale programına katılanların programı daha yüksek derecedeki değişim basamağıyla bitirdikleri, müdahale sonunda fiziksel şiddetti azalttıkları ve tekrar şiddete başvurma ihtimallerinin azaldığı gözlenmiştir (Lila, Gracia, ve Catala-Minana, 2018). Görüldügü gibi motivasyonel görüşmenin standart müdahale hizmetlerine entegre olması katılımcıların davranış değişimine katkı sağlamıştır.

Flört dönemindeki duygusal ilişkilerde en az bir kez şiddet davranışları sergileyen erkeklerin iki saat motivasyonel görüşmenin uygulandığı müdahaledeki davranış değişimleri incelendiğinde; motivasyonel görüşmeye katılan kişilerde fiziksel saldırganlıkta ve alkol kullanımında dokuz aylık ve daha fazla süredeki müdahalenin sonunda önemli derecelerde azalmalar gözlemlenmiştir. Ayrıca dokuz aylık tedavi sürecinin sonunda psikolojik saldırganlığ uyguladıkları şiddetin sorumluluğunu almada artışlar görülmüştür (Woodin ve O'Leary, 2010). Motivasyonel görüşmenin uygulandığ 1 iyileştirme süreçlerine düzenli olarak devam eden kişilerin şiddet davranışlarını kabul edecekleri ve sorumluluk alarak sağlıklı duygusal ilişkiler geliştirebilecekleri öngörülür.

\section{Kültüre duyarlı müdahale yaklașımları}

Kültürel hassasiyetlerin ve özelliklerin göz ard1 edilmesi yetersiz ve başarılı olmayan hizmetlere neden olmaktadır. Farklı kültürel ve etnik yapıların insan davranışları üzerindeki etkisini göz önüne aldığımızda kültüre duyarlı yaklaşımlardan bahsetmek kıymetli olacaktır. Kişilerin geçmişini anlama çabasıyla başlayan müdahale hizmetleri onların katılımını olumlu yönde etkileyebilir. Örneğin, iyileştirme sürecinin başında geliştirilecek olumlu terapötik ilişki kişilerin etnik, kültürel geçmişi ve diğer sosyal yapılarını anlamayla yakından ilişkilidir (Walling vd., 2012). 
Standart aile içi şiddet failleri müdahale merkezlerinde çoğu kez kültürel dinamikler göz ardı edilmektedir (Almeida ve Dolan-Delvecchio, 1999). Aile içi şiddetin sosyal problemlerle, ataerkil sosyal inançlarla, cinsiyetçi rollerle, dini inançlarla ve göçmenlikle ilişkili sorunlarla bağlantılı olduğu alanyazında ifade edilmiştir (Jayasundara, Nedegaard, Sharma, ve Flanagan, 2014). Başka ülkelerden göç etmiş aile içi şiddet faillerinin daha karmaşık tecrübeleri kabul edilerek bu kişilerin sosyal ve kültürel değerleri dikkate alınarak uygulanacak olan bir tedavi yaklaşımının daha etkili sonuçlara erişmesi ön görülmektedir. Özellikle toplumdaki farklı etnik kökenli bireylerin ya da göçmenlerin muhtemel ayrımcılık ve bask1 altına girme durumları uzmanlar tarafindan dikkate alınarak aile içi şiddet vakalarını değerlendirmeleri gerekmektedir (Atkinson, Thompson, ve Grant, 1993). Kültüre duyarlı yaklaşımların temelinde kişilerin göçmenlikle ilgili yaşantıları, yeni bir topluma ve kültüre geçiş ve adapte olma süreçlerini anlamak yer almaktadır (Almeida ve Dolan-Delvecchio 1999).

Kadına karşı şiddetin kültürel normları ve sosyal yapısını değiştirmek için birincil müdahale yaklaşımı kadına karşı şiddet konusunda sosyal medya aracılığıyla toplumsal farkındalığı artırmaktır. Bu farkındalığın içeriğginde yeni bir kültürel çevreye alışmaları için toplumun yapısı ve kurallarıyla ilgili bilgiler paylaşmak, aile içi şiddet konusundaki yanlış inanışları fark ettirmek yer alır (Aldarondo ve Castro-Fernandez 2008). Farklı kültür ve etnik kökenli faillerin sağlıklı ve saygılı duygusal ilişkiler geliştirmelerinde yardımcı olabileceğine dair bazı veriler paylaşılmıștır. Tüm bu veriler göz önünde bulundurulurken, uzmanların bu kişilere karşı önyargılı olmaması ve onların şiddet davranışlarını kültürün bir parçasıymış gibi algılamamaları gerektiğine de dikkat çekilmektedir (Aldarondo ve Castro-Fernandez 2008). İnsanların etnik yapıları ne olursa olsun aile içindeki şiddet bir insan hakkı ihlali olarak kabul edilerek gerekli müdahale hizmetlerinin sunulması gerekir.

Sosyal ve kültürel yapılardan bahsederken cinsiyetçi rol tutumları, kontrol ve güç dengesinin sağlanmasında ataerkil sosyal yapıların ağırlığının ne kadar etkili olduğu unutulmamalıdır (Yllo ve Straus, 1990). Ataerkil sosyal yapıların düşünce sistemini ve davranışları etkilediğine yönelik vurgular yapılmaktadır. Örneğin, erkeğin kadına biçmiş olduğu cinsiyetçi roller ve beklentiler ataerkil yapılarla açıklanabilmektedir (Kandiyoti, 1988). Sosyal yapının insan davranışları üzerindeki etkisi göz önüne alındığında, aile içi şiddet faillerinin iyileştirilmesi sosyal ve kültürel yapılara duyarlı tekniklerle daha etkili ve başarılı şekilde gerçekleşebilir. Kültüre duyarlı yaklaşımları göz önünde bulundurmak farklı kültürel ve sosyal geçmişi olan kişiler için faydalı olacaktır (Williams ve Becker, 1994). Bu müdahale sürecinin zor ola- cağ planlanmış ve uzun süreçli bir iyileştirme programında şiddetsiz davranışların geliştirilebileceği aşikâr olup, bu konuda çalışan ve çalışacak olan meslek elemanlarının bilgilerinin arttırılması ve pratik uygulamalar kullanmaları başarılı sonuçlara ulaşmada kilit rol oynayacaktır.

Aile içi şiddet faillerinin müdahale hizmetlerine katılımlarını artırmak; yeni ve olumlu davranışları kazanmaları için en uygun yaklaşımlara ve teorilere başvurmak faillerin davranış değişimine katkı sağlar. S1klıkla başvurulan bilişsel-davranıșçı teknikler ve son yıllarda önemine dikkat çekilen motivasyonel görüşmenin ortak kullanımı istenilen sonuçlara ulaşmada yardımcı olabilir. Sayısız araştırmacı şiddet faillerinin birbirinden çok fark11 karakteristik özelliklere, kültürel geçmişe, genetik ve psikolojik yapıya sahip olduğuna işaret ederek, tek tip bir yaklaşımın şiddeti durdurmada etkili olamayacağının altını çizmiştir (Bent-Goodley, Rice II, Williams, ve Pope, 2007; Cantos ve O'Leary, 2014; Dutton ve Sonkin, 2000; O’Neal ve Beckman, 2016; Williams ve Becker, 1994).

\section{Yaklașımların Birlikte Kullanılması}

Bilişsel-davranışçı, motivasyonel görüşme ve kültüre duyarlı yaklaşımların aile içi şiddet failleri üzerindeki etkisi ve faydası derinlemesine incelenmiș ve bütünleyici ve çoklu yaklaşımların bir arada kullanılmasının daha etkili ve olumlu sonuçlara erişebileceği sonucuna varılmıştır. Pek çok çalışma tek başına bilişsel-davranışçı tekniklerin ya da feminist yaklaşımların başarılı olamayacağını saptamıştır (Kelly ve Johnson, 2008; Thornton, Graham-Kevan, ve Archer, 2010). Örneğin, kişilik bozuklukları ve ruhsal rahatsızlıkların şiddeti tetikleyen sebepler olabileceği belirtilmiştir (Johnston ve Campbell, 1993). Bu tür rahatsızlığa sahip kişilerden sadece \%5'inin ilaçla tedavi aldıktan sonra tekrar şiddete başvurmadıkları belirtilmiştir (Johnston ve Campbell, 1993). Bu sonuca göre ilaçla tedavinin yanında ek müdahale hizmetlerine duyulan ihtiyaç gözler önüne serilmiştir.

Şiddetin nedenleri arasında öfke (Murphy ve Eckhardt, 2005; Babcock, vd., 2004); kişilik problemleri (Johnston ve Campbell, 1993); geçmiş yaşantılar ve sosyal ve kültürel yapılar (Walling vd., 2012) olmak üzere dört ana unsur öne çıkmıştır. Bu dört unsurun şiddet davranışıyla yakından ilişkili olduğu vurgulanırken, diğer kişisel- ailesel, toplumsal ilişkilere bağlı olarak çok farklı faktörlerin ve çevresel koşulların şiddete sebep olabileceği göz ardı edilmemelidir. Bu makale uzmanlara bir yol gösterici olması amacıyla kilit iyileştirme tekniklerinin ve başarısının neler olabileceği konusunda bir 1şık tutmayı hedeflemiştir. Tüm bu incelemeler ve tartışmalar sonucunda birbiriyle etkileşim içinde olan tekniklerin katılımcıların ihtiyaçlarına göre uygulanması aşağıdaki Tablo 1'de gösterilmiştir. 
Tablo 1. Şiddeti Değerlendirme Süreci, İyileştirme Teknikleri ve Etkileri

Şiddet nedenleri
Şiddetin değerlendirme süreçleri
İyileștirme tekniği
Tekniklerin etkileri ve bașarısı
Vakayla ilgili dava dosyalarının incelenmesi, görüşlerin değerlendirilmesi, hastahane ya da varsa

Öfke hapishane notlarının dikkate alınması. Siddet uygulayan kişinin olay olmadan önce öfke duygusuna kapılıp kapılmadığının kararı verilir.
Öfke kontrolü tekniklerini uygulama: öfkeyle ve tetikleyici unsurlarıyla ilgili kişilerin farkındalığını artırma, problemlerle başa çıma becerisi kazandırma, iletişim becerisini geliștirme ve rahatlama teknikleridir (Novaco, 1997).
Şiddet faillerinin her zaman öfke duygusu ile şiddet davranışları arasında bir ilişkinin olmadığı; karmaşık ve farklı faktörlerin ve karakteristik özelliklerin şiddeti ortaya çıkardığı göz önünde bulundurularak diğer tekniklerle birlikte uygulanan öfke kontrolü teknikleri etkili olacaktır.
Psikiyatrik değerlendirmelerin yapılmasi; paranoid, histeriyonik, antisosyal ve narsistik kişilik bozukluklarının belirlenmesi için kișilik bozukluğu envanterleri ve testlerinin uygulanması.
Kişilik problemleriyle ilișkili olarak şiddet uygulayan faillere ruhsal hastalıklar uzmanı psikiyatrist gözetiminde iyileştirme teknikleri uygulanabilir. Motivasyona görüşme müdahalenin başında uygulanabilir.
Bu tür vakalarda geliștirilecek olan terapötik ilişki ve motivasyonel görüşmenin başlangıçta uygulanması müdahalenin etkisini artırabilir
Ana amaç çevresel, bilişsel, duygusal olayları inceleyerek şiddeti tetikleyen unsurları tanımlayabilmektir. Şiddet faillerine açık uçlu sorularla şiddete iten olayları anlatması istenir. Örneğin, yaşadığınız stresli bir olay sizi nasıl etkiler? Bu stres sizi nasıl şiddete iter? Kavga sırasında ne düșünürsünüz ve hissedersiniz? Şiddet öncesi nasıl bir hal alırsınız?
Ara verme yöntemi kişilerin kendilerini kızgın ya da öfkeli hissettikleri zamanlarda şiddet uygulama ihtimali olduğunu fark ettikleri anda bulundukları ortamı terk etmeleri gerektiğini öğretir. Bilişsel-davranışçı yaklaşımlar bu tür vakalarda kullanılır.
Uyguladıkları şiddetin zarar verici sonuçlarını görememiş bireylerde bilişsel-davranışçı tekniklerin etkisi zayif olurken, değişim için hazır olan katılımcılar üzerinde daha etkilidir.
Cinsiyetçi kültürel yapılar, göçmenliğe bağlı olarak yaşanan rrkçılık ve ayrımcilık olayları ya da yeni bir topluma alışmadaki zorlukların değerlendirilmesi gerekir.
Bilişsel-davranışçı tekniklerle feminist yaklaşımlar ataerkil sosyal yapıyı kırarak erkeklerin sorumluluk alarak daha eşitlikçi davranışlar geliştirmesine yardımcı olabilir. Kültüre dayalı yaklaşımlar kişinin kendine has sorun alanlarını anlarını anlar.
Uzmanların kendilerini geliştirerek farklı etnik kökenli bireyleri ötekileștirmeden başvuracakları kültüre dayalı yaklaşımlarla başarılı sonuçlara erişebilirler. 
Tablo 1 şiddeti değerlendirme süreçleri, müdahale teknikleri ve etkilerini gösterirken, bilişsel-davranışçı yaklaşımlara, motivasyonel görüşmeye ve kültüre duyarlı yaklaşımlara vurgu yapmıştır. Bu makale daha sağlıklı ve güçlü hizmetlerin sunulmasına katkı sağlanmayı umut etmiştir. Aile içi şiddet müdahale hizmetlerindeki uygulamaların daha başarılı olması için sosyal politika yapıcılar da tek tip bir sistem yerine farklı ve ihtiyaca bağlı yaklaşımların uygulanmasının ne kadar faydalı olacağını fark etmelidir. Bununla birlikte müdahale hizmetlerinin adalet sistemi, sağlık hizmetleri, kadın konuk evleri ve çocuk esirgeme kurumu gibi kurumlarla koordineli ve işbirliği içerisinde çalışmalarını zorunlu kılan bir yapının tesis edilmesi başarılı sonuçlara erişmede kilit rol oynar. Örneğin, aile içi şiddet faillerinin müdahale hizmetlerine katılımlarının yanında çocuk esirgeme kurumlarıyla iletişime geçmesi onların uyguladıkları şiddetin çocuk üzerindeki olumsuz ve zarar verici etkilerini anlamasına yardımcı olduğu saptanmıştır (Kelly ve Westmarland, 2015). Tüm bunları dikkate aldığımız zaman kurumlar arası işbirliği ve koordineli çalışma ilkesiyle çoklu yaklaşımları birlikte kullanan hizmetlerin geliştirilmesi aile içi şiddet sonlandırılmasına katkı sağlayacağı önerilmektedir.

\section{Tartışma}

Müdahale merkezlerinde aile içi şiddet faillerinin şiddet davranışlarını sonlandırmak için kullanılan yaklaşımların kendi içinde zayıf ve güçlü yönleri olduğu görülmektedir. Her müdahale yaklaşımı kişilerin ihtiyaç durumlarına göre fayda sağlayabilir. Şiddet sebeplerini etkili bir şekilde değerlendirdikten sonra uygun yaklaşımlar saptanıp doğru yöntemler uygulanması gerekmektedir. Farklı sorun alanlarına çözüm bulmaya yönelik geliştirilen kişilere özel iyileştirme planı çerçevesinde aile içi şiddet failleri olumlu ve sağlıklı davranışlar oluşturma konusunda ilerleme kaydedebilirler. Bu makale özellikle bilişsel-davranışçı teknikler, motivasyonel görüşme ve kültüre duyarlı stratejiler üzerinde durarak ana problem alanlarına çözüm bulmaya yönelik öneriler sunmuştur. Bu makale kişilerin müdahale hizmetlerine aktif katılımları için isteklilikleri üzerinde durarak olumlu bir terapötik ilişki geliştirmenin önemine dikkat çekmiştir. Olumlu bir terapötik ortam oluşturulduktan sonra daha eğitici teknikler uygulanabilir. Örneğin, kat1lan kişiler şiddet davranışlarını sorgulamaya başladıkları zaman sorumluluk alarak yeni ve olumlu davranışlar geliştirme çabası gösterebileceklerdir.

Her kişinin kendine has bir hikâyesi, kültürel dinamikleri ve etnik geçmişi olduğu göz önünde bulundurularak, ayrımcılık ya da küçümseme ve yıpratma gibi uygulamalara sebep olunmaması gerekir. Bunun için geliştirici ve adaletli bir müdahale hizmetlerinin yapılandırılmasıyla ve meslek elemanlarının bu konuda gerekli eğitimleri almasıyla başarılı sonuçlara erişeceği önerilmektedir. $\mathrm{Bu}$ öneri yapılırken kültüre dayalı yaklaşımlardan bahsedilerek etkili aile içi şiddet müdahale hizmetlerinin geliştirilmesi hedeflenmiştir. Tüm bunları göz önünde bulundurduğumuz zaman kapsamlı ve titizlikle hazırlanacak olan müdahale yaklaşımlarının ancak uzmanın yardımı ve çabasıyla aile içi şiddet failleri daha sağlıklı, saygılı ve olumlu bir duygusal ilişki geliştirme becerisini kazanabileceklerdir. 


\section{Kaynaklar}

Aldarondo, E., \& Castro-Fernandez, M. (2008). Intimate partner violence and recidivism following interventions with men who batter: cultural and empirical considerations. In R. Carrillo \& J. Tello (Eds.), Family Violence and Men of Color (pp. 1-37). New York: Springer Publishing Company.

Allen, Christopher, T. (2010). Engaging men in violence prevention: Empirically examining theoretical barriers and catalysts. University of South Carolina.

Almeida, R. V, \& Dolan-Delvecchio, K. en. (1999). Addressing culture in batterers intervention. Violence against Women, 5(6), 654-683.

Andrews, D. A., \& Bonta, J. (2003). Psychology of criminal conduct ( $3 r d$ ed.). Cincinnati, $\mathrm{OH}$ : Anderson.

Atkinson, D. R., Thompson, C. E., \& Grant, S. K. (1993). A three-dimesional model for counseling racial/ethnic minorities. The Counseling Psychologist, 21(2), 257-277.

Babcock, J. C., Green, C. E., \& Robie, C. (2004). Does batterers' treatment work? A meta-analytic review of domestic violence treatment. Clinical Psychology Review, 23(8), 1023-1053. https://doi. org/10.1016/j.cpr.2002.07.001

Beck, R., \& Fernandez, E. (1998). Cognitive-behavioural therapy in the treatment of anger: A meta-analysis. Cognitive Therapy and Research, 22, 63-74.

Bent-Goodley, T. B., Rice II, J., Williams, O. J., \& Pope, M. (2007). Treatment for perpetrators of domestic violence. In M. P. Koss \& A. E. Kazdin (Eds.), Violence against women and children, Vol 2: Navigating solutions (2nd ed., pp. 199-213). American Psychological Association.

Campbell, J. C. (2004). Helping women understand their risk in situations of intimate partner violence. Journal of Interpersonal Violence, 19(12), 1464 1477. https://doi.org/10.1177/0886260504269698

Cantos, A. L., \& O’Leary, K. D. (2014). One size does not fit all in the treatment of intimate partner violence. Partner Abuse, 5(2), 204-236.

Cavanaugh, M. M., Solomon, P., \& Gelles, R. J. (2011). The dialectical psychoeducational workshop (DPEW): The conceptual framework and curriculum for a preventative intervention for males at risk for IPV. Violence against Women, 17(8), 970989. https://doi.org/10.1177/1077801211414266

Crane, C. A., \& Eckhardt, C. I. (2013). Evaluation of a single-session brief motivational enhancement intervention for partner abusive men. Journal of Counseling Psychology, 60(2), 180-187.
Daniels, J. W., \& Murphy, C. M. (1997). Stages and processes of change in batterers' treatment. Cognitive and Behavior Practice, 4(1), 123-145. https://doi. org/10.1016/S1077-7229(97)80015-6

Debbonaire, T., Debbonaire, E., \& Walton, K. (2003). Evaluation of work with domestic violence abusers in Ireland. Bristol: UK.

Deffenbacher, J. L., Oetting, E. R., \& DiGiuseppe, R. A. (2002). Principles of empirically supported interventions applied to anger management. The Counselling Psychologist, 30, 262-280.

Del Vecchio, T., \& O'Leary, K. D. (2004). Effectiveness of anger treatments for specific anger problems. A Meta-Analytic Review. Clinical Psychology Review, 24, 15-34.

DiGiuseppe, R., \& Tafrate, R. (2003). Anger treatment for adults: A meta-analytic review. Psychotherapy, 28, 70-84.

Dobash, R. E., Dobash, R. P., Cavanagh, K., \& Lewis, R. (2000). Changing violent men. Thousand Oaks, CA: Sage.

Dunford, F. W. (2000). The San Diego Navy experiment: An assessment of interventions for men who assault their wives. Journal of Consulting and Clinical Psychology, 68, 468-476.

Dutton, D. G., \& Sonkin, D. J. (2000). Introduction: perspectives on the treatment of intimate violence. In D. Dutton \& D. J. Sonkin (Eds.), Intimate Violence: Contemporary Treatment Innovations (pp. 47-74). New York: The Howarth Maltreatment and Trauma Press.

Eckhardt, C. I., Holtzworth-Munroe, A. Norlander, B., Sibley, A., \& Cahill, M. (2008). Readiness to change, partner violence subtypes, and treatment outcomes among men in treatment for partner assault. Violence and Victims, 23(4), 446-475. https://doi.org/10.1891/0886-6708.23.4.446

Eckhardt, Christopher I, Murphy, C., Black, D., \& Suhr, L. (2006). Intervention programs for perpetrators of intimate partner violence: Conclusions from a clinical research perspective. Public Health Report, 121, 369-381.

Eryurt, M. A., \& Seçkiner, P. Ç. (2015). Consequences of Violence against Women. In I. Yuksel-Kaptan, A. Cavlin, \& B. A. Ergocmen (Eds.), Research on domestic violence against women in Turkey (pp. 129-153). Republic of Turkey Ministry of Family and Social Policies.

Gondolf, E. W. (1987). Changing men who batter: A developmental model for integrated interventions. Journal of Family Violence, 2, 335-349.

Heckert, D. A., \& Gondolf, E. W. (2004). Battered women's perceptions of risk versus risk factors and instruments in predicting repeat reassault. Journal of Interpersonal Violence, 19(7), 778-800. https:// doi.org/10.1177/0886260504265619 
Howells, K., Day, A., Williamson, P., Bubner, S., Jauncey, S., Parker, A., \& Heseltine, K. (2005). Brief anger management programs with offenders: Outcomes and predictors of change. The Journal of Forensic Psychiatry \& Psychology, 16(2), 296311. https://doi.org/10.1080/14789940500096099

İstanbul Sözleşmesi. (2011). Kadına Yönelik Şiddet ve Aile İçi Şiddetin Önlenmesi ve Bunlarla Mücadeleye Dair Avrupa Konseyi Sözleşmesi. İstanbul.

Jayasundara, D., Nedegaard, R., Sharma, B., \& Flanagan, K. (2014). Intimate partner violence in Muslim communities. Art and Social Science Journal, 1-12. https://doi.org/10.4172/2151-6200.S1-003

Johnston, J. R., \& Campbell, L. E. G. (1993). A clinical typology of interparental violence in disputed-custody divorces. American Journal of Orthopsychiatry, 63, 190-199.

Kandiyoti, D. (1988). Bargaining with patriarchy. Gender \& Society, 2(3), 274-290. https://doi. org/10.1177/089124388002003004

Kelly, J., \& Johnson, M. (2008). Differentiation among types of intimate partner violence: Research update and implications for interventions. Family Court Review, 46(3), 476-499.

Kelly, L., \& Westmarland, N. (2015). Domestic violence perpetrator programmes: steps towards change. Project Mirabal Final Report. London and Durham: London Metropolitan University and Durham University.

Lawson, D. M., \& Brossart, D. (2009). Attachment, interpersonal problems, and treatment outcomes in group therapy for partner violent men. 10(288301), Psychology of Men and Masculinity. https:// doi.org/10.1037/ a0017043

Lawson, David M, Kellam, M., Quinn, J., \& Malnar, S. G. (2012). Integrated cognitive-behavioral and psychodynamic psychotherapy for intimate partner violent men. Psychotherapy, 49(2), 190-201. https://doi.org/10.1037/a0028255

Lila, M., Gracia, E., \& Catala-Minana, A. (2018). Individualized motivational plans in batterer intervention programs: A randomized clinical trial. Journal of Counselting and Clinical Psychology, 4(86).

Livesley, W. J. (2001). Handbook of personality disorders: Theory, research and treatment. London: Guilford.

Lomo, B., Haavind, H., \& Tjersland, O. A. (2016). From resistance to invitations: How men voluntarily in therapy for intimate partner violence may contribute to the development of a working alliance. Journal of Interpersonal Violence, 33(16), 1-23. https://doi.org/10.1177/0886260516628290
Mavili, A. (2014). Aile içi şiddet kadının ve çocuğun korunması (2.). Ankara: Elma Yayınevi.

Morrel, T. M., Elliott, J. D., Murphy, C. M., \& Taft, C. T. (2003). Cognitive behavioral and supportive group treatments for partner violent men. Behavior Therapy, 34, 77-95. https://doi.org/10.1016/S00057894(03)80023-0

Murphy, Christopher M., Eckhardt, C. I., Clifford, J. M., Lamotte, A. D., \& Meis, L. A. (2017). Individual versus group cognitive-behavioral therapy for partner-violent men: a preliminary randomized trial. Journal of Interpersonal Violence, 1-23. https:// doi.org/10.1177/0886260517705666

Murphy, Christopher Mark, \& Eckhardt, C. I. (2005). Treating the abusive partner: An individualized cognitive-behavioral approach. New York: Guilford Press.

Musser, P. H., Semiatin, J. N., Taft, C. T., \& Murphy, C. M. (2008). Motivational interviewing as a pregroup intervention for partner-violent men. $\mathrm{Vi}$ olence and Victims, 23(5), 539-557. https://doi. org/10.1891/0886-6708.23.5.539

Novaco, R. (1997). Remediating anger and aggression with violent offenders. Legal and Criminological Psychology, 2, 77-88.

O’Neal, E. N., \& Beckman, L. O. (2016). Intersections of race , ethnicity, and gender: Reframing knowledge surrounding barriers to social services among Latina intimate partner violence victims. Violence Against Women, 23(5), 1-23. https://doi. org/10.1177/1077801216646223

Palmstierna, T., Haugan, G., Jarwson, S., Rasmussen, K., \& Nøttestad, J. A. (2012). Cognitive-behaviour group therapy for men voluntary seeking help for intimate partner violence. Nordic Journal of Psychiatry, 66, 360-365. https://doi.org/10.3109/08039 488.2012.665080

Pence, E., \& Paymar, M. (1993). Education groups for men who batter: The Duluth model. Springer Publishing Company.

Prochaska, J. O., \& DiClemente, C. C. (1982). Transtheoretical therapy: Toward a more integrative model of change. Psychotherapy, 19(3), 276-288.

Saunders, D. G. (2009). 8. Programs for men who batter. In E. Stark \& E. S. Buzawa (Eds.), Violence against Women in Families and Relationships [3 volumes] (3rd ed., pp. 161-178). Prager: ABCCLIO.

Saunders, Daniel G. (1996). Feminist-cognitive-behavioral and process-psychodynamic treatments for men who batter: interaction of abuser traits and treatment models. Violence and Victims, 11(4), 393-414. 
Silvergleid, C. S., \& Mankowski, E. S. (2006). How batterer intervention programs work: Participant and facilitator accounts of processes of change. Journal of Interpersonal Violence, 21(1), 139-159. https:// doi.org/10.1177/0886260505282103

Simmons, C., \& Lehmann, P. (2009). Strengths-based batterer intervention: A new direction with a different paradigm. In P. Lehmann \& C. Simmons (Eds.), Strengths-Based Batterer Intervention: A New Paradigm in Ending Family Violence. (pp. 39-43). New York: Springer Publishing Company.

Smedslund, G., Dalsbø, T. K., Steiro, A. K., Winsvold, A., \& Clench-Aas, J. (2007). Cognitive behavioural therapy for men who physically abuse their female partner. The Cochrane Database of Systematic Reviews, (3), 1-25. https://doi. org/10.1002/14651858.CD006048.pub2

Taft, C. T., Macdonald, A., Creech, S. K., Monson, C. M., \& Murphy, C. M. (2016). A randomized controlled clinical trial of the Strength at Home men's program for partner violence in military veterans. Journal of Clinical Psychiatry, 77, 1168-1175.

Taft, C. T., Murphy, C. M., King, D. W., Musser, P. H., \& DeDeyn, J. M. (2003). Process and treatment adherence factors in group cognitive-behavioral therapy for partner violent men. Journal of Consulting and Clinical Psychology, 71, 812-820. https://doi. org/10.1037/0022-006X.71.4.812

Taft, Casey T., \& Murphy, C. M. (2007). The working alliance in intervention for partner violence perpetrators: recent research and theory. Journal of Family Violence, 22(1), 11-18. https://doi.org/10.1007/ s10896-006-9053-z

TÜİK. (2014). Kadına yönelik aile içi şiddet istatistikleri. Retrieved from http://www.tuik.gov.tr/VeriTabanlari.do?ust_id=109\&vt_id=31

Varley Thornton, A. J., Graham-Kevan, N., \& Archer, J. (2010). Adaptive and maladaptive personality traits as predictors of violent and nonviolent offending behavior in men and women. Aggressive Behavior, 36(3), 177-186. https://doi.org/10.1002/ ab. 20340

Walker, J. S., \& Bright, J. A. (2009). Cognitive therapy for violence: reaching the parts that anger management doesn't reach. The Journal of Forensic Psychiatry \& Psychology, 20(2), 174-201. https://doi. org/10.1080/14789940701656832

Walling, S. M., Suvak, M. K., Howard, J. M., Taft, C. T., \& Murphy, C. M. (2012). Race/ethnicity as a predictor of change in working alliance during cognitive behavioral therapy for intimate partner violence perpetrators. Psychotherapy (Chicago, Ill.), 49(2), 180-189. https://doi.org/10.1037/a0025751
WHO. (2013). Global and Regional Estimates of Violence against Women: Prevalence and Health Effects of Intimate Partner Violence and Non-Partner Sexual Violence. Geneva.

Williams, O. J., \& Becker, L. R. (1994). Domestic partner abuse treatment programs and cultural competence: the results of a national survey. Violence and Victims, 9(3), 287-296.

Wistow, R., Kelly, L., \& Westmarland, N. (2016). "Time Out": A strategy for reducing men's violence against women in relationships? Violence Against Women, 23(6), 730-748. https://doi. org/10.1177/1077801216647944

Woodin, E. M., \& Leary, K. D. O. (2009). Theoretical approaches to the etiology of partner violence. In D. J. Whitaker \& J. R. Lutzker (Eds.), Preventing partner violence research and evidence based intervention strategies (pp. 41-65). American Psychological Association.

Woodin, E. M., \& O'Leary, K. D. (2010). A brief motivational intervention for physically aggressive dating couples. Prevention Science, 11, 371-383. https:// doi.org/10.1007/s11121-010-0176-3

Yllo, K., \& Straus, M. A. (1990). Patriarchy and violence against wives; the impact of structural and normative factors. In M. A. Straus \& R. J. Gelles (Eds.), Physical violence in American families: Risk factors and adaptations to violence in 8, 145 families (pp. 383-399). Transaction Publishers.

Yüksel-Kaptanoğlu, İ., \& Çavlin, A. (2015). Kadına yönelik şiddet yaygınlığı. In I. Yuksel-Kaptan, A. Cavlin, \& B. A. Ergocmen (Eds.), Türkiye'de Kadına Yönelik Aile içi Şİddet Araştırması (pp. 81-125). Ankara: TC Aile ve Sosyal Politikalar Bakanlığı. 


\title{
Summary \\ Domestic Violence: The Effectiveness of Intervention Approaches to Stop Perpetrators' Violent Behaviour
}

\author{
Zeynep Turhan \\ Bartın University
}

\begin{abstract}
Domestic violence perpetrator intervention programmes play a significant role in reducing and stopping violent behaviour. Interventions challenge perpetrators to understand the consequences of violence on family members. The purpose of this article is to investigate how existing domestic violence perpetrator intervention approaches and models effectively reduce and stop perpetrators' violent and abusive behaviour. This investigation hopes to help the facilitators in interventions recognise how some intervention techniques might be more efficient based on the participants' circumstances and characteristics. Different strategies and approaches have been used in domestic violence interventions. This research focuses on the importance of implementing integrated approaches based on the risk factors and perpetrators' characteristics and needs. The major purpose of this article is to illustrate the importance of using integrated and pluralistic approaches together to end perpetrators' violent behaviour. It is suggested that an integrated cognitive-behavioural approach, motivational interviewing and culturally-sensitive approaches can increase the success of domestic violence perpetrator interventions.

Several scholars argue that different types of intervention approaches should be implemented to reduce and end domestic violence. The law of 6284, the Protection of the Family and the Prevention of Violence Against Women is important for ensuring the security of the family members as this law includes critical and vital protective orders for survivors in Turkey. Moreover, this law tries to make the perpetrators accountable for their violent and abusive behaviour by restricting them to stay with family members in the same home or even prison sanction. To provide effective domestic violence intervention programmes, the effectiveness of intervention approaches will be detailed in the following sections.

Feminist theories and cognitive-behavioural approaches are the main approaches to understanding and preventing men's violent behaviour in many inter-
\end{abstract}

ventions. For example, the Duluth model (Pence and Paymar, 1993) and cognitive-behavioural approaches (Murphy and Eckhardt, 2005) play a significant role in reducing violent behaviour and encouraging the men to implement healthier and respectful attitudes towards their partners. Even though there is no systematic intervention programmes or centres for perpetrators of domestic violence in Turkey, this article pays attention to the existing domestic violence perpetrator intervention approaches in developed countries and their effectiveness in stopping violent behaviour. When we are aware of the effectiveness of intervention approaches, then we can implement appropriate intervention strategies based on the participants' needs.

\section{The effectiveness of intervention approaches}

The Duluth model is a form of the feminist social-psychological approaches and this model emphasizes the importance of reducing gendered-based violence by focusing on power imbalance in an intimate relationship, the patriarchal social structure and men's privilege (Pence and Paymar, 1993). Furthermore, the Duluth model pays attention to the importance of developing a more egalitarian intimate relationship for a healthy and respectful environment in a family setting (Pence and Paymar, 1993). Cognitive-behavioural approaches include many intervention techniques. The main techniques are anger management, time-out strategy, developing relationship skills and changing the beliefs around the patriarchal structure to end domestic violence (Christopher Mark Murphy and Eckhardt, 2005). As seen in these techniques, there are some differences between these approaches. For example, while feminist approaches focus more on patriarchal structures and gendered attitudes, cognitive-behavioural approaches concentrate on the risk factors for violent behaviour such as belief systems, genetic structure, patriarchal social structure, substance abuse and psychopathological factors (Allen,

Address for Correspondence: Assoc. Prof. Zeynep Turhan, Bartın University, Faculty of Health Sciences, Department of Social Work, Campus of Ağdacı, 74100 Bartın

E-mail: zturhan@bartin.edu.tr 
Christopher, 2010; Erica M Woodin and Leary, 2009). Therefore, these different emphasis of the approaches needs to be well recognised and applied based on the participants' needs during interventions.

\section{Motivational interviewing}

Given some characteristics of common approaches (e.g. Duluth model, feminist approach and cognitive-behavioural approaches) in domestic violence perpetrator interventions, the examination of the effectiveness of motivational interviewing in interventions might be beneficial as this has been recently paid attention in domestic violence field. For example, motivational interviewing highlights the importance of the participants' motivation and enthusiasm in implementing new and non-violent behaviour. Motivational approaches focus on the perpetrators' readiness to change in interventions (Musser, Semiatin, Taft, and Murphy, 2008). A great number of researchers found that perpetrators are often unwilling to participate in interventions and change their behaviour (Daniels and Murphy, 1997; Prochaska and DiClemente, 1982).

In recent years, strength-based approach has been identified as one of the most important approaches (Simmons and Lehmann, 2009). According to strengths-based approach, the techniques should focus on the person as a whole and consider the individuals who hold their strengths and abilities to develop themselves in a safe environment (Simmons and Lehmann, 2009). Increasing awareness about themselves plays an important role in strengthening interpersonal relationships. As a result, individuals who are ready to change can dramatically benefit from intervention services because they hold the level of motivation.

\section{Cognitive behavioural therapy}

The major techniques in cognitive behavioural therapy include anger management techniques and timeout. These techniques will be identified as important and common interventions in reducing and ending violent and abusive behaviour. Their effectiveness on the perpetrators' behavioural change process should be examined by recognising their benefits as well as limitations during interventions.

Anger management is one of the important intervention approaches in the process of domestic violence perpetrators interventions (Howells et al., 2005). While some findings stated that anger management techniques are effective, there are some questions about the level of success of these techniques among some perpetrators of domestic violence (Howells et al., 2005). Even though some studies found the relationship between anger and aggression or violent behaviour, it has also been ob- served that anger is not always associated with violent and abusive behaviour. For example, it has been pointed out that aggression might occur without anger (Howells et al., 2005). As a result, many different situations and conditions around violent behaviour should be investigated to provide a comprehensive assessment. It is recommended that anger management techniques should be taken into account during interventions if the reasons for violent behaviour are associated with the elements of anger

In the cognitive behavioural approaches, the most frequently used technique is a time-out. Time-out is an interruption technique that aims to avoid applying violent behaviour. The technique of time-out is one of the important ways to stop violence (Wistow, Kelly, and Westmarland, 2016). The method of time-out teaches people to leave their environment as soon as they realize that there is a possibility of being violent when they feel angry. In such cases, when the person leaves that environment, this can help him to control himself and not to apply violent or abusive behaviour. Some studies have been conducted to understand whether this technique is useful or how effective it is. For example, Gondolf, (1987) found that time-out technique helps the perpetrators to stop violence by assisting them to control their behaviour. However, time-out can be successfully implemented if perpetrators hold a certain level of self-efficacy and confidence about being able to apply this technique (Gondolf, 1987).

\section{Culturally-sensitive approaches}

According to the culturally-sensitive approaches, the individuals who have migrated a new country need to develop their information about the structure and rules of the new society to understand a new cultural environment (Aldarondo and Castro-Fernandez 2008). When they learn the new rules and law in a new society, they can recognize their misconceptions about domestic violence. Culturally-sensitive approaches might help develop healthy and respectful emotional relationships for perpetrators of different cultural and ethnic backgrounds. Therefore, the professionals who work with these groups should not be prejudiced against them and that they should not perceive the violence as a cultural issue (Aldarondo and Castro-Fernandez 2008). As a result, it is emphasized that violence against women and violence in the family are considered as violations of human rights and necessary intervention services should be provided.

\section{Discussion}

In the above sections, the effectiveness and benefits of motivational interviewing, cognitive-behavioural 
therapy and culturally-sensitive approaches on perpetrators of domestic violence are examined. As a result of this study, it is concluded that the combination of and multiple approaches could achieve more effective and positive outcomes. It is recommended to apply the techniques as an integrative way based on the participants' unique needs. Four factors have been identified as important risk factors for violent behaviour. These are anger, personal problems and personal history based on environmental, cognitive and emotional issues. While these four reasons are stated as important risks for violent behaviour, many other factors related to personal-family or societal issues might be involved in the perpetrators' violent behaviour as risk factors. When the facilitators recognise these risk factors around violent behaviour, they can use the most appropriate interventions techniques. This can ensure the effective interventions for perpetrators of domestic violence. 